\title{
Relationship between Sleep Disturbance and Polypharmacy among Hospitailzed Elderly
}

\section{Sara A. Hamza ,. Heba G Saber ${ }^{1}$,Nesma AM Hassan ${ }^{1}$}

1Department of Geriatric Medicine, Faculty of Medicine, Ain Shams University.

\begin{abstract}
Background: Sleep disturbances are common problems among elderly with multiple morbidities on multiple medication, that affect quality of life of elderly.
\end{abstract}

Aim: to study the relationship between polypharmacy and sleep disturbances among elderly patients and factors affecting this relation.

Methods: A cross sectional study which included 100 elderly participants, hospitalized in Demerdash. Pittsburgh sleep quality index using Arabic version was used to detect sleep disturbance.

Results: The study showed significant relationship between component 2 of the Pittsburgh sleep quality index (sleep duration), where most the patient showed moderate difficulty with $p$ value 0.03 . There was also a significant relationship between component 3 (sleep latency) and polypharmacy, with $p$ value 0.002 . A highly significant relationship between increasing age and sleep disturbance was found; $48 \%$ of those over 80 had sleep problems while only $12.5 \%$ of patient between $60-61$ had sleep problems, with $p$ value $<0.001$. Our study demonstrated a highly significant relationship between the presence of multiple morbidities and increasing sleep problems with $p$-value $<$ 0.001 .

Conclusions: Age related sleep disorders increases among elderly with polypharmacy, and this significantly affects quality of life.

Keywords: Polypharmacy, Sleep Disturbance, Hospitalized Elderly

\section{Background}

Aging induces many changes in sleep architecture, many studies suggests that older adults are particularly vulnerable (1). Although changes in sleep architecture are to be expected with increasing age, age itself does not result in disturbed sleep. But it is the ability to sleep that decreases with age, which may be due to other associated factors with aging (2). Sleep disturbance is common in older adults because aging is associated with an increasing prevalence of multiple morbidities and polypharmacy ${ }^{(3)}$.

Medication use is another factor that may increase risk for sleep disturbances in older adults. Polypharmacy may also contribute to heightened risk for sleep disturbance in older adults ${ }^{(3)}$.

Polypharmacy is associated with adverse outcomes including mortality, falls, adverse drug reactions, increased length of stay in hospital and readmission to hospital soon after discharge ${ }^{(4)}$. The risk of adverse effects and harm increases with increasing numbers of medications ${ }^{(5)}$.
The use of multiple drugs more than 5 drugs is defined by many authors as polypharmacy ${ }^{(6)}$. Polypharmacy is really common as age-related morbidities increase, putting the elderly at risk for drug-drug and drugdisease interactions ${ }^{(7)}$.

Medications can affect sleep in many ways; even those that are prescribed for insomnia can produce unhelpful side effects ${ }^{(8)}$.

Multimorbidity, defined by Diederichs et al. ${ }^{(9)}$ as the coexistence of 2 or more chronic diseases. Multimorbidity is related to aging and became growing global public health challenge in elderly with multiple chronic condition.

\section{Methods}

This is a cross sectional study done at El Demerdash Hospital which concluded 100 elderly males and females, 60 years and older.

Inclusion Criteria: 
Males and females, 60 years and older hospitalized in Demerdash Hospital.

Exclusion Criteria:

Those who refused to participate in the study and Demented elderly.

Study Procedures:

1- Full Medical History

Detailed history of chronic diseases e.g multi morbidities is 2 or more chronic conitions ${ }^{(9)}$. Drug history if more than 5 medication in one month consider polypharmacy ${ }^{(6)}$.

\section{2- Physical Examination}

General and local examination with special concern to cardiovascular, neurological and musculoskeletal systems.

3- $\quad$ The Pittsburgh Sleep Quality Index (PSQI) is a self-rated questionnaire which assesses sleep quality and disturbances over a 1-month time interval ${ }^{(10)}$.

\section{Statistical Analysis:}

Data were collected, revised, coded and entered to the Statistical Package for Social Science (IBM SPSS) version 20.

The quantitative data were presented as mean, standard deviations and ranges when their distribution found parametric while non-parametric data were presented as median with interquartile range (IQR) and qualitative data were presented as number and percentages.

The comparison between groups regarding qualitative data was done by using Chi-square test and/or Fisher exact test only when the expected count in any cell was less than 5 .

The comparison between two independent groups with quantitative data and parametric distribution was done using Independent t-test while data with non-parametric distribution was compared using Mann-Whitney test.

Generalized linear regression was done to assess predictors, among the assessment tools, of frailty domains.

The confidence interval was set to $95 \%$ and the margin of error accepted was set to $5 \%$. The p-value was considered significant as the following:

$\mathrm{P}>0.05$ : Non-significant $\mathrm{P}<0.05$ : Significant $\mathrm{P}<$ 0.01: Highly significant.

\section{Results}

The study was conducted on 100 hospitalized patients, 51 were females and 49 were males. According to age, 19 patients were in 60-69 years age group, 40 patients were $70-79$, and 49 patients over 80 .

By asking the patient we found that 79 out of 100 patients were taking more than 4 drugs.

Table 1: Relationship between aging and sleep disturbance

Age Pittsburgh sleep

\begin{tabular}{|c|c|c|c|c|c|}
\hline & \multicolumn{2}{|c|}{$\begin{array}{l}\text { No sleep } \\
\text { problem }\end{array}$} & \multicolumn{2}{|c|}{ Sleep problem } & \multirow[t]{2}{*}{$\begin{array}{l}\mathrm{P} \\
\text { value }\end{array}$} \\
\hline & $\mathrm{N}$ & $\%$ & $\mathrm{~N}$ & $\%$ & \\
\hline $\begin{array}{l}\text { 60-69 } \\
\text { Years }\end{array}$ & 9 & 45.00 & 10 & 12.50 & 0.0001 \\
\hline $\begin{array}{l}70-79 \\
\text { Years }\end{array}$ & 9 & 45.00 & 31 & 38.75 & \\
\hline$>=80 \backslash$ & 2 & 10.00 & 39 & 48.75 & \\
\hline
\end{tabular}

This table shows that there's a highly significant relationship between increasing age and sleep disturbance, $48 \%$ of the patient over 80 have sleep problems while only $12.5 \%$ of patient between $60-61$ have sleep problems, with $\mathrm{p}$ value $<0.001$.

Table 2: Relationship between multi morbidities and sleep disturbance

\begin{tabular}{cccccc}
\hline $\begin{array}{c}\text { Multi } \\
\text { morbidities }\end{array}$ & \multicolumn{4}{c}{ Pittsburgh sleep } & \multicolumn{1}{c}{$\begin{array}{c}\mathbf{P} \\
\text { value }\end{array}$} \\
\cline { 2 - 6 } & $\begin{array}{c}\text { No sleep } \\
\text { problem }\end{array}$ & \multicolumn{2}{c}{$\begin{array}{c}\text { Sleep } \\
\text { problem }\end{array}$} & $<\mathbf{0 . 0 0 1}$ \\
& $\mathbf{N}$ & $\%$ & $\mathbf{N}$ & $\%$ & \\
Yes & 8 & 40.00 & 72 & 90.00 & \\
No & 12 & 60.00 & 8 & 10.00 & \\
\hline
\end{tabular}

Table 3: Relationship between sleep disorders using PSQI and polypharmacy

\begin{tabular}{|c|c|c|c|c|c|}
\hline \multirow{3}{*}{$\begin{array}{c}\text { Poly } \\
\text { pharmacy }\end{array}$} & \multicolumn{4}{|c|}{ Pittsburgh sleep } & \multirow{3}{*}{$\begin{array}{c}\begin{array}{c}P \\
\text { value }\end{array} \\
<0.001\end{array}$} \\
\hline & \multicolumn{2}{|c|}{$\begin{array}{l}\text { No sleep } \\
\text { problem }\end{array}$} & \multicolumn{2}{|c|}{$\begin{array}{c}\text { Sleep } \\
\text { problem }\end{array}$} & \\
\hline & $\mathbf{N}$ & $\%$ & $\mathbf{N}$ & $\%$ & \\
\hline Yes & 9 & 45.00 & 70 & 87.50 & \\
\hline No & 11 & 55.00 & 10 & 12.50 & \\
\hline
\end{tabular}

This table shows a highly significant relationships between sleep problems and polypharmacy, $87 \%$ of elderly who take more than 5 medication in one month has sleep problems with pvalue $<0.001$.

Table 4 showed significant relationship between component 2 (sleep duration) where most of the patients showed moderate difficulty, with $\mathrm{p}$ value 0.03 , and it also shows a significant relationship between component 3 (sleep latency) and polypharmacy where most patients had severe difficulty with $p$ value 0.002 .

\section{Discussion}

Polypharmacy and sleep disturbance are common in elderly because aging is associated with an increasing prevalence of multiple morbidities, Medication use is another factor that may increase risk for sleep disturbances in older adults ${ }^{(3)}$.

In elderly, there are changes in sleep architecture, increased risk for sleep disorders, circadian rhythm shifts, multiple mental \& physical morbidities, polypharmacy, institutionalization and likely a combination of these factors are possible factors contributing to older adult sleep disturbance ${ }^{(11)}$.

The current study is a cross-sectional study to determine relationship between sleep disturbance and polypharmacy in hospitalized elderly in El Demerdash Hospital. 
Table 4: Components of sleep Pittsburgh sleep index and polypharmcy

\begin{tabular}{|c|c|c|c|c|c|c|c|c|}
\hline & & \multicolumn{6}{|c|}{ Poly pharmacy } & \multirow[b]{3}{*}{ P-value } \\
\hline & & \multicolumn{2}{|c|}{ Yes } & \multicolumn{2}{|c|}{ No } & \multicolumn{2}{|c|}{ Total } & \\
\hline & & $\mathrm{N}$ & $\%$ & $\mathrm{~N}$ & $\%$ & $\mathrm{~N}$ & $\%$ & \\
\hline \multirow[t]{4}{*}{ Comp 1} & No difficulty & 19 & 24.05 & 6 & 28.57 & 25 & 25.00 & \multirow{4}{*}{0.875} \\
\hline & Mild difficulty & 11 & 13.92 & 4 & 19.05 & 15 & 15.00 & \\
\hline & Moderate difficulty & 44 & 55.70 & 10 & 47.62 & 54 & 54.00 & \\
\hline & Severe difficulty & 5 & 6.33 & 1 & 4.76 & 6 & 6.00 & \\
\hline \multirow[t]{4}{*}{ Comp 2} & No difficulty & 21 & 26.58 & 5 & 23.81 & 26 & 26.00 & \multirow[t]{4}{*}{$0.030 *$} \\
\hline & Mild difficulty & 17 & 21.52 & 11 & 52.38 & 28 & 28.00 & \\
\hline & Moderate difficulty & 36 & 45.57 & 5 & 23.81 & 41 & 41.00 & \\
\hline & Severe difficulty & 5 & 6.33 & 0 & 0.00 & 5 & 5.00 & \\
\hline \multirow[t]{4}{*}{ Comp 3} & No difficulty & 29 & 36.71 & 6 & 28.57 & 35 & 35.00 & \multirow[t]{4}{*}{$0.002 *$} \\
\hline & Mild difficulty & 30 & 37.97 & 3 & 14.29 & 33 & 33.00 & \\
\hline & Moderate difficulty & 19 & 24.05 & 8 & 38.10 & 27 & 27.00 & \\
\hline & Severe difficulty & 1 & 1.27 & 4 & 19.05 & 5 & 5.00 & \\
\hline \multirow[t]{4}{*}{ Comp 4} & No difficulty & 42 & 53.16 & 11 & 52.38 & 53 & 53.00 & \multirow[t]{4}{*}{0.703} \\
\hline & Mild difficulty & 27 & 34.18 & 9 & 42.86 & 36 & 36.00 & \\
\hline & Moderate difficulty & 8 & 10.13 & 1 & 4.76 & 9 & 9.00 & \\
\hline & Severe difficulty & 2 & 2.53 & 0 & 0.00 & 2 & 2.00 & \\
\hline \multirow[t]{4}{*}{ Comp 5} & No difficulty & 28 & 35.44 & 9 & 42.86 & 37 & 37.00 & \multirow[t]{4}{*}{0.180} \\
\hline & Mild difficulty & 25 & 31.65 & 10 & 47.62 & 35 & 35.00 & \\
\hline & Moderate difficulty & 21 & 26.58 & 2 & 9.52 & 23 & 23.00 & \\
\hline & Severe difficulty & 5 & 6.33 & 0 & 0.00 & 5 & 5.00 & \\
\hline \multirow[t]{4}{*}{ Comp 6} & No difficulty & 22 & 27.85 & 7 & 33.33 & 29 & 29.00 & \multirow[t]{4}{*}{0.096} \\
\hline & Mild difficulty & 35 & 44.30 & 10 & 47.62 & 45 & 45.00 & \\
\hline & Moderate difficulty & 19 & 24.05 & 1 & 4.76 & 20 & 20.00 & \\
\hline & Severe difficulty & 3 & 3.80 & 3 & 14.29 & 6 & 6.00 & \\
\hline \multirow[t]{3}{*}{ Comp 7} & No difficulty & 16 & 20.25 & 3 & 14.29 & 19 & 19.00 & \multirow[t]{3}{*}{0.075} \\
\hline & Mild difficulty & 48 & 60.76 & 9 & 42.86 & 57 & 57.00 & \\
\hline & Moderate difficulty & 15 & 18.99 & 9 & 42.86 & 24 & 24.00 & \\
\hline
\end{tabular}

This study shows a statistically significant relationship between aging and prevalence of sleep disturbance, that agrees with studies by Wolkove et al. (12) that showed that by aging the prevelance of sleep disorders increases. Several other studies, including those by Vas Fragoso et al. (13) and Ancoli-Israel (14) also concurred with our results.

Multiple morbidities are related to Sleep Quality in elderly, they are the main cause of poor sleep quality. The current study shows a highly significant relationship between the presence of multiple morbidities and sleep quality this goes with study by This coincides with studies by Wolkove et al. (12); Ancoli-Israel (14) Roth et al. (15) and Marques et al. (16) that also show strong relationship between multiple morbidities and sleep disturbance

A statistically significant relationship between sleep disturbances and polypharmacy, in our study sleep duration and sleep latency are affected in elderly with polypharmacy that concides with a study by Vázquez et al. (8). Which also stated that sleep latency in elderly is impaired with polypharmacy. Doi et al. (17) found that among participants in their respective studies the most affected component of Pittsburgh sleep quality index in comparison to healthy individuals are sleep duration and sleep latency.

In our study sleep duration is impaired related to increased medication use study by Lande and Gragnani (18) disagrees with the current study showed that increasing number of medications did not influence total sleep time.

\section{CONCLUSION}

Sleep disturbance increases by aging.

Multimorbidities and polypharmacy are risk factors of sleep disturbance.

Age related sleep disorders increases among elderly with polypharmacy, and this significantly affects quality of life. 


\section{References}

1. Roepke S and Ancoli-Israel S (2010): Sleep disorders in the elderly. Indian J Med Res 131: 302-310

2. Ancoli-lsrael $S$ and Ayalon $L$ (2006): The diagnosis and treatment of sleep disorders in older adults. Am J Geriatr Psychiatry; 14: 95-103.

3. Fried TR, O'leary J, Towle V, Goldstein MK, Trentalange M and Martin DK (2014): Health outcomes associated with polypharmacy in community dwelling older adults: A systematic review. Journal of the American Geriatrics Society; 62(12): 2261-2272.

4. Caughey GE, Roughead EE, Vitry AI, McDermott RA, Shakib S and Gilbert AL (2010): Comorbidity in the elderly with diabetes: Identification of areas of potential treatment conflicts. Diabetes Research and Clinical Practice; 87(3): 385-393.

5. Maher RL, Hanlon J and Hajjar ER (2014): Clinical consequences of polypharmacy in elderly. Expert Opin Drug Saf.; 13(1): 57-65.

6. Hines LE and Murphy JE (2011): Potentially harmful drug-drug interactions in the elderly: a review. The American Journal of Geriatric Pharmacotherapy; 9(6): 364-377.

7. Qato DM, Wilder J, Schumm L, Gillet V and Alexander $G$ (2016): CHanges in prescription and overthe-counter medication and dietary supplement use among older adults in the united states, 2005 vs 2011. JAMA Internal Medicine; 176(4): 473-482.

8. Vázquez VG, Macías JF, del Teso Alonso F, las Heras González RM, Alvarez AH and Carretero JA (2000): The quality of sleep associated with polypharmacy. Atencion Primaria; 26(10): 697-9.

9. Diederichs C, Berger K and Bartels DB (2010): The measurement of multiple chronic diseases a systematic review on existing multimorbidity indices. Journals of Gerontology Series A: Biomedical Sciences and Medical Sciences; 66(3): 301-11.

10. Ancoli-lsrael $S$ and Ayalon $L$ (2006): The diagnosis and treatment of sleep disorders in older adults. Am J Geriatr Psychiatry; 14: 95-103.

11. Fried TR, O'leary J, Towle V, Goldstein MK, Trentalange M and Martin DK (2014): Health outcomes associated with polypharmacy in community dwelling older adults: A systematic review. Journal of the American Geriatrics Society; 62(12): 2261-2272.

12. Caughey GE, Roughead EE, Vitry Al, McDermott RA, Shakib S and Gilbert AL (2010): Comorbidity in the elderly with diabetes: Identification of areas of potential treatment conflicts. Diabetes Research and Clinical Practice; 87(3): 385-393.

13. Maher RL, Hanlon J and Hajjar ER (2014): Clinical consequences of polypharmacy in elderly. Expert Opin Drug Saf.; 13(1): 57-65.

14. Hines LE and Murphy JE (2011): Potentially harmful drugdrug interactions in the elderly: a review. The American Journal of Geriatric Pharmacotherapy; 9(6): 364-377.

15. Qato DM, Wilder J, Schumm L, Gillet V and Alexander G (2016): CHanges in prescription and over-the-counter medication and dietary supplement use among older adults in the united states, 2005 vs 2011. JAMA Internal Medicine; 176(4): 473-482.

16. Vázquez VG, Macías JF, del Teso Alonso F, las Heras González RM, Alvarez AH and Carretero JA (2000): The quality of sleep associated with polypharmacy. Atencion Primaria; 26(10): 697-9.

17. Diederichs C, Berger $K$ and Bartels DB (2010): The measurement of multiple chronic diseases a systematic review on existing multimorbidity indices. Journals of Gerontology Series A: Biomedical Sciences and Medical Sciences; 66(3): 301-11. 